\title{
Gender differences in attrition rates of hospital-based medical specialty programs: attributable to gender composition of the clinical specialty?
}

Olivia Butterman ( $\mathbf{D}$.butterman@capaciteitsorgaan.nl)

Stichting Capaciteitsorgaan https://orcid.org/0000-0002-9129-116X

\section{Victor Slenter}

Stichting Capaciteitsorgaan

\section{Lud Van der Velden}

Netherlands Institute for Health Services Research

\section{Ronald Batenburg}

Netherlands Institute for Health Services Research

\section{Research}

Keywords: gender, attrition rates, medical training, clinical specialisms

Posted Date: July 29th, 2020

DOI: https://doi.org/10.21203/rs.3.rs-26858/v2

License: @ (i) This work is licensed under a Creative Commons Attribution 4.0 International License. Read Full License 


\section{Abstract}

Background Since 1999 the Advisory Committee on Medical Manpower Planning (ACMMP) advises the Dutch government on the medical workforce capacity and the intake in training programs, as to achieve or maintain a balance on the labour market. One of the key parameters the ACMMP uses when calculating the required intake in training programs, is the attrition rate. Methods In total 11,579 trainees enrolled in hospital-based programs from January 1 st 2003 until 31 st of December 2012, for 26 specialisms. To explore possible explanations for the gender differences in attrition rate per specialty, additional information was gathered: the percentage of males per program, the total number of specialists in training, the duration of the training and the percentage of males currently working in that specialty. Results One training program was excluded, due to the small size of that training program (62 trainees) and the large outliers it produced. Regression analyses were done, showing significant explanations of the variation in the difference between male and female attrition rates (Y1), for the proportion of males working in the profession per 01-01-2003 ( 2 : .545, $F(27,60), p<.000)$, the proportion of males in training per 01-01-2003 ( $2: .417, F(16,01), p<.000)$ and a small effect for the relationship with the total attrition rate for each training program $(R 2: .163, F(4,46), p<.046)$. There was also a significant effect for the duration of the specialty training ( 2 : .299, $F(9,85), p<.005)$. A Kruskal-Wallis test was preformed to analyse the difference in attrition by type of specialty. The difference between the types of specialisms were significant $(H=6,66, p .0,036)$. Conclusions Attrition rates in Dutch hospital-based specialty programs differ between males and females in a way that more males tend to drop-out from training when the specialty is dominated by women and, importantly, vice versa as well. The relationships found needs to be explored, in particular as the duration and nature of the specialty training seem to interact with gender ratios in the training programs and occupations longer training programs tend to have more males on them. Furthermore, more insight is needed in the selection and identification processes among residents in specialty training.

\section{Background}

In virtually every country in the world, the demand of health and social workers will increase steadily over the next decade. Projections indicate that the demand will rise to 80 million workers, which is almost double the supply in the base year (2013, 41 million health workers) (19). The World Health Organisation estimated that this leads to a healthcare workforce gap of around 14.5 million by 2030 (26). Health workforce planning is crucial in selecting and implementing the correct policy measures to address the issues of future shortages timely $(21,18)$. The Netherlands has a long tradition in health workforce planning for physicians (12). Since 1999 the Advisory Committee on Medical Manpower Planning (ACMMP; "Capaciteitsorgaan") advises the Dutch government and sector stakeholders on the medical workforce capacity and the intake in training programs. The latest reports, presented to the government in December 2019, encompass 79 professions and $145,000 \mathrm{fte}$ within the health care sector (5). Internationally, the planning and policy model governed by the ACMMP is considered as a 'best practice', as there have been relatively low shortages in most of the medical workforce occupations since the system of health workforce planning started in 1999 (7).

The ACMMP advises, amongst other professions, on the census-based intake in 26 hospital-based specialty programs for doctors of medicine (MD). A MD can apply for a training position within a hospital-based specialty program after obtaining a Master's degree in Medicine, which, in the Netherlands, consists of a 3-year Bachelor followed by a 3-year Master program at medical school.

One of the key parameters the ACMMP take into account when calculating the required intake in training programs to achieve or maintain a balance on the labour market, is the attrition rate. For this article we used the attrition rate of cohorts of hospital-based training programs where all trainees have completed or left the training program. The attrition rate of surgical specialties in particular gains attention in the literature, particularly in the United States $(22,17,6)$. The meta-analysis 
on prevalence and causes of attrition among surgical residents, performed by Zeyad Khoushhal and his colleagues sheds light on one particular finding: attrition is significantly higher among female trainees compared to males ( $25 \%$ and $15 \%$ respectively) (17). There has been a particular literature review on gender differences in the learning and teaching of surgery (9). The literature review by Carmen Burgos and Anna Josephson shows a complex myriad of factors that contribute to gender differences in teaching and learning surgery, particularly the lack of female role models as a result of underrepresentation of women in surgical academia (9). While there is research on surgical specialties and the differences in attrition rates due to the lack of female role models, there does not seem to be research on gender differences in attrition rates in specialties where there are more female doctors and hence less male role models.

The empirical bases of this paper is the availability of data on attrition rates since 2003 for all the hospital-based specialties in the Netherlands. In general the last decade, attrition rates vary between $10 \%-12 \%$, with outliers ranging from $26,4 \%$ to $3 \%$ $(1,2,3,4)$. Although attrition rates have been published per specialism, for several periods, little attention has been paid so far to their differences by gender. At the beginning of the data time series, the reason for this was lack of statistical power: for some specialties the group of males or females within a particular hospital-based specialty program was too small to calculate the attrition rates by gender. But as the database on attrition rates has expanded over the last two decades, these data limitations are considerably reduced. Based on data that allows analyses on gender differences within attrition rates per specialty in the Netherlands, the aim this paper is to describe these differences and explain them from different perspectives.

\section{Methods}

Aim and design: The aim of this study is to gain insight into the differences between attrition of male and female hospitalbased specialists in training.

Description of the data set: The analyses were based on a historical database of attrition rates, calculated and retrieved from the Dutch Registration Committee Medical Specialists ("Registratiecommissie Geneeskundig Specialismen"). This Committee has extensive, detailed and up to date information on all medical specialists in training in the Netherlands, their planned training program, including all the cases of attrition. Although older data sets were available, data from the Registration Committee Medical Specialists was retrieved and compiled from $1^{\text {st }}$ of January 2003 until July 2018. The attrition rates were calculated by specialty and gender for the period $1^{\text {st }}$ of January 2003 until the $31^{\text {st }}$ of December 2012 . This way it was ensured that most of the hospital-based specialists in training included in the database (almost) had finished their training program. Hospital-based specialty programs in the Netherlands last 5 to 6 years and most of the attrition takes place in the first or second year $(24,27,10)$.

The dataset used consists of aggregated numbers per specialty training program: the number of males and females in training, the number of males and females who left training, and in which year of their training they dropped-out. None of these figures were traceable to individuals. In total 11,579 trainees enrolled in hospital-based programs from January $1^{\text {st }}$ 2003 until December $31^{\text {st }} 2012$, for 26 specialisms. Table 1 is based on these 11,579 enrolees of which 4,868 were male and 6,711 were female (58\%) and shows the attrition rates per training program for both males and females. An extra column was added, calculating the difference between male and female attrition (male attrition rate minus female attrition rate). To explore possible explanations for the gender differences in attrition rate by specialty, four additional characteristics of the specialities and their training program was gathered and added to the dataset (see Table 1 as well): (1) the percentage of 
males per program, (2) the total number of specialists in training, (3) the duration of the training and (4) the percentage of males currently working in that specialty.

\section{Statistical analysis:}

To analyse the relationship between the gender differences in attrition rates and the four possible contributing factors, linear regression analyses were done for the 26 specialties. A Kruskal-Wallis test was performed to analyse the relationship between gender differences in attrition rate and type of speciality.

Variables: The dependent variable (Y1) was the difference in male and female attrition for the inflow cohorts between 20032013, measured in percentages (male attrition rate minus female attrition rate). The four independent variables that were included in the linear regression analyses were:

- $\mathrm{X} 1$ : \% of males in training (as of 01-01-2003),

- X2: \% of males working in that specialism (as of 01-01-2003),

- X3: total attrition rate (for the inflow cohorts between 2003-2013),

- X4: formal duration of training in years.

The fifth independent variable that was included in the Kruskal-Wallis test was:

- X5: the type of speciality by three categories: auxiliary, non-surgical or surgical (see Table 1, categories are equal for 2003-2013).

Statistical program: The data were analysed in MiniTab, version 19.

\section{Results}

Descriptive results: Figure 1 depicts the difference in attrition rate between males and females, per specialty. This gender difference (projected on the $x$-axis) is positive if the attrition rate is higher for males in training, and negative if the difference is higher for females. Specialties are sorted on the $y$-axis by the proportion of females in training between 2003 and 2013.

Outlier analysis: In figure 1, the specialty cardiothoracic surgery is excluded as this appears to a clear outlier. For this specialty the difference in attrition between males and females was $-42 \%$ (i.e. the attrition rate for female trainees in cardiothoracic surgery was $42 \%$ higher compared to male trainees), where the average for all specialties was $-2,7 \%$. This outlier result is probably due to the fact that the attrition rate for cardiothoracic surgery is based on a total of only 62 trainees in 10 years (2003-2013), while the average number of trainees for the other training programs is 445 . Including this outlier clearly skewed the distribution of the dependent variable Y1 in the data set (Anderson-Darling value: 1.260), whereas excluding it changed the distribution to a normal distribution (Anderson-Darling value: 0.886). The outlier analysis is depicted by Figures $\mathbf{2}$ (with cardiothoracic surgery) and $\mathbf{3}$ (without cardiothoracic surgery). Based on this, it was decided to exclude cardiothoracic surgery as a specialty for further analysis.

Next, four linear regression analyses were executed to explain the variation in Y1, gender differences in attrition rate, by the dependent variables $\mathrm{X} 1$ to $\mathrm{X} 4$ at the level of the 25 specialties or training programmes (hence excluding cardiothoracic surgery). Below we present the results in order of the prediction strength of the dependent variables. After this, and as 
mentioned above, a Kruskal-Wallis test was performed to analyse the relation between the gender differences in attrition rate and type specialty training (X5).

Results of the regression analyses showed the strongest predictor for $\mathrm{X} 2$, the proportion of males working in the profession per 01-01-2003. More than a half (55\%) of the variation in the difference in attrition rates is explained by this dependent variable, a significant finding $\left(R^{2}: 0.545, F(27.60), p<.000\right)$. Figure 4 depicts this result. The regression model shows that residuals were normally distributed, giving no signs for other outliers. Also, the prediction interval for the regression model equation felt within the $95 \%$ boundaries.

The negative and significant coefficient implies that the lower the percentage of males working in a speciality, the higher the difference in attrition rate between males and females that are training for that specialty (top left hand of the fitted line plot, figure 4). Specifically, in the specialties with lower percentages of males working, males have higher drop-out rates compared to females in training. The opposite can obviously be concluded as well, as the lower right end of the fitted line plot in figure 4 implies: in specialties with more males working in that profession, the drop-out rate of females in training is significantly higher.

Another regression analysis was done for the relationship between $\mathrm{Y} 1$ and the $\mathrm{X} 1$, the proportion of males in training. This analysis showed that $42 \%$ of the variation in the gender difference in attrition rates was explained by this predictor, as significant finding $\left(R^{2}: 0.417, F(16.01), p<0.000\right)$, and depicted by Figure 5. Residuals were normally distributed, the prediction interval for this regression equation felt within the $95 \%$ boundaries. This negative and significant coefficient implies that the lower the percentages of males in training in a specialty, the higher the difference in attrition between males and females in training for that speciality (top left hand of the fitted line plot, figure 5). In contrast to the previous regression analysis result however, the specific result is that less male residents drop-out if the proportion of males is higher in a specialty. And vice versa, shown by the lower right end of the fitted line plot (figure 5): if specialties have more males in training, more females will stop their training before completion, i.e. females have significant higher attrition rates.

A third regression analysis was done to analyse the relationship between difference in male and female attrition rates and the total attrition rate for each training program $(X 3)$. The result can be summarized as a relative small but significant effect $\left(R^{2}: 0.163, F(4.46), p<0.046\right)$. From Figure 6, it can be derived that for specialty training programs where the overall attrition rates are higher, the difference in attrition between males and females is higher as well (top/right side of figure 6). Likewise, in specialties where the overall drop-out rates in the training program are lower, the difference in attrition between males and females in training for that speciality is lower as well (bottom/left side of figure 6).

A fourth regression analysis was performed to explore the relationship between the difference in attrition between males and females in training, and the duration of the specialty training (X4). In sum, it can be showed this relation is negative and significant $\left(R^{2}: 0.299, F(9.85), p<0.005\right)$, see figure 7. Longer specialty training programs thus show larger differences in attrition between males and females in training. 
In a final step, the differences between the specialties as such were explored (X5), in particular the distinction between surgical and other specialties. This is partly related to the previous analysis as most surgical specialties also have the highest training duration. A Kruskal-Wallis test was preformed to analyse the difference in attrition between males and females in training by type of specialty. The difference between the types of specialisms were significant $(H=6.66, p=0.036)$. The ranking results of the Kruskal-Wallis test implied that the gender differences in attrition rate was negative for 'surgical' specialisms (Z-value -1.98), positive for 'auxillary' specialisms (Z-value 2.29) and ranked in between for the 'non-surgical' specialisms (Z-value -0.11).

\section{Discussion}

Historical data (2003-2013) on attrition from 25 Dutch hospital-based medical specialty training programs were analysed, to gain insight in the differences between male and female residents and their attrition rate by specialty. Significant relationships were found between gender differences in attrition rate on the one hand, and the gender composition of both the specialism and the training program on the other hand. There is also a relationships between gender differences in attrition rate, the duration of the program, the overall attrition rates and the surgical versus non-surgical type of specialties. These latter relationships can be interactive as male dominated training programs tend to be surgical and thus longer in duration whereas female dominated programs are non-surgical and shorter in duration.

Although there have been publications on higher attrition rates for females in surgical training programs where males are the majority in training and occupation (17), to our knowledge, no outcomes have been previously reported that similarly more males tend to drop-out from training programs where women outnumber men. This highly interesting result might by explained from social identity theory.

Social identity theory "refers to an individual's self-concept in relation to his or her membership of social groups" (8, p.144). This concept of self-categorisation, e.g. whether or not an individual identifies his or herself with other members of the group, might explain our results. It implies that male and female residents differ in whether or not s/he identifies him or herself with the specific speciality, depending on their fit with this 'accessible group'. It requires further study how and why male and female specialists in training either match with in-group differences versus out-group differences depending on the gender composition and other characteristics of the specialty (8). While a male student in training in a female 'dominated' profession might (subconsciously) not identify as easily with the group identity as his female counterpart in training, the opposite can also be the case as our results imply. Selection and segregation theory might shed further light on the roots of this identification process (11). These theories point at persistent gender differences in job values and aspirations that shape choices about what types of skills to seek in the course of education. Young men are held to emphasize economic wealth, status, and prestige in their definition of an ideal job, whereas for women the social and altruistic opportunities offered by the job are more important $(20,13,23)$. These 'social expectations' regarding job-related gender roles become internalized as preferences (13), and can be reinforced by 'intergenerational transmission of field choices', i.e. that youngsters are likely to follow their parents' footsteps (25). According to Hearn and Olzak (14) women also place more weight on supportive departmental culture and positive personal interactions with teaching staff, whereas men on the external rewards. Another relevant finding by Solnick (23) in line with segregation theory, is that women at women's colleges were more likely to switch into traditionally male-dominated fields during college, than are women enrolled at coeducational institutions because of the supportive cultural and academic environments in women's colleges. 
Mentorship during training of medical specialists plays a significant, albeit informal, role for young people in their training as medical specialist. In line with 'social identity theory' (8) it seems important for people in training to have a mentor with whom s/he can identify, partly based on demographics. Most of the studies on mentorship during (surgical) training have been performed on women (15), but obviously the same could be true for males, i.e. that they might need a role model in the case they are underrepresented.

In addition to social and gender-related explanations, other explanations might also coincidentally apply for both male and female residents. In a Dutch survey on attrition, factors such as 'disturbed work-life balance', 'job content other than expected', 'workload too heavy' and 'specialty culture unappealing' were the most noted factors for leaving training, both for men and women (10). These reasons might be magnified due to lack of identification with the group identity of the specialty.

The implications of our findings is that in trying to resolve attrition issues it is relevant to further analyse data from larger groups to understand trends in attrition and factors that could possibly be of influence. In striving to create a divers medical workforce, it is important to identify and break through the patterns of attrition that maintain or amplify gender unbalances of some of the specialties. In this respect, a limitation of this study is that qualitative information is not included to explore and interpret the reasons for the attrition. Future research could focus on relating the different reasons for attrition with the attrition patterns we found by gender and specialty. The reasons for attrition among Dutch medical trainees found by Bustraan and colleagues (10) provide useful input for such research. Although it should be recognized that their study is limited to residents who left training between January 2014 and September 2017.

\section{Conclusions}

Attrition rates in Dutch hospital-based specialty programs differ between males and females in a way that more males tend to drop-out from training when the specialty is dominated by women and vice versa. These results were based on a complete nation-wide database, with historical data of over 11,000 trainees from 1st of January 2003 until the 31st of December 2013. Still, the relationships found need to be explored, in particular how the duration and nature of the specialty training interacts with the gender ratios in the medical training programs and occupations - as these factors are also related to gender differences in attrition rates. Furthermore, more insight is needed in the selection and identification processes among residents in specialty training.

\section{Declarations}

\section{Ethics approval and consent to participate}

Not applicable.

\section{Consent for publication}

Not applicable.

\section{Availability of data}

The datasets generated during and/or analysed during the current study are not publicly available due the contractual agreement with Registration Commissie Geneeskundig Specialismen but are available from the corresponding author on reasonable request.

\section{Competing interests}


The authors declare that they have no competing interests.

\section{Funding}

Not applicable.

\section{Author's contributions}

LV prepared the data set for analysis and did the first comparisons. OB did further analyses in Minitab. OB, VS, RB and LV wrote the manuscript. OB compiled the figures.

Acknowledgements: Acknowledgements to the editors of the Dutch Journal of Medicine ('Nederlands Tijdschrift voor Geneeskunde', or NTvG) who asked us about possible differences between male and female attrition and gave us an idea for this exploration.

\section{Abbreviations}

ACMMP $\quad$ Advisory Committee on Medical Manpower Planning

MD Medical Doctor

\section{Literature}

1. ACMMP. Capaciteitsplan 2010. Deelrapport 1: Medische en klinisch technologische specialisten. Capaciteitsorgaan. 2010.

2. ACMMP. Capaciteitsplan 2013. Deelrapport 1. Capaciteitsorgaan. 2013.

3. ACMMP. Capaciteitsplan 2016. Deelrapport 1. Capaciteitsorgaan. 2016.

4. ACMMP. Capaciteitsplan 2020-2023. Deelrapport 1. Capaciteitsorgaan. 2019.

5. ACCMP. Capaciteitsplan 2021-2024. Hoofdrapport. Capaciteitsorgaan. 2019.

6. Bauer JM, Holt GE. National Orthopedic Residency Attrition: Who Is At Risk?, J of Surg Education, 2016; 73 (5): $852-857$. https://doi.org/10.1016/j.jsurg.2016.03.010.

7. Britnell M. Human: Solving the global workforce crisis in health care. Oxford University Press. 2019.

8. Burford BC. Group processes in medical education: learning from social identity theory. Med Educ. 2012; 46: 143-152. https://doi-org.proxy.uba.uva.nl:2443/10.1111/j.1365-2923.2011.04099.x

9. Burgos CM, Josephson A. Gender differences in the learning and teaching of surgery: a literature review. Int J Med Educ. 2014; 5: 110-124.

10. Bustraan, J et al. Why Do Trainees Leave Hospital-Based Specialty Training? A Nationwide Survey Study Investigating Factors Involved in Attrition and Subsequent Career Choices in the Netherlands. BMJ Open. 2019; 9.6: e028631.

11. Gerber, TP, Cheung, SY. Horizontal Stratification in Postsecondary Education: Forms, Explanations, and Implications. Annu Rev Sociol; 2008; 34: 299-318.

12. Van Greuningen M. Health workforce planning in the Netherlands: How a projection model informs policy regarding the general practitioner and oral health care workforces. Ipskamp. 2016. 
13. Halaby, C. Where Job Values Come From: Family and Schooling Background, Cognitive Ability, and Gender. Am Sociol Rev. 2003; 68: 251-278.

14. Hearn JC, Olzak S. The role of college major departments in the reproduction of sexual inequality. Sociol. Educ. 1981; 54: 195-205.

15. Hoover, EL. Mentoring women in academic surgery: overcoming institutional barriers to success. J Natl Med Assoc. 2006; 98: 1542-1545.

16. Jonsson JO. Explaining sex differences in educational choice: an empirical assessment of a rational choice model. Eur. Sociol. Rev. 1999; 15: 391-404.

17. Khoushhal Z, Hussain MA, Greco E, et al. Prevalence and Causes of Attrition Among Surgical Residents: A Systematic Review and Meta-analysis. JAMA Surg. 2017; 152(3): 265-272. doi:https://doiorg.proxy.uba.uva.nl:2443/10.1001/jamasurg.2016.4086.

18. Kroezen M, Van Hoegaerden M, Batenburg R. The Joint Action on Health Workforce Planning and Forecasting: results of a European programme to improve health workforce policies. Health Policy 2018; 122(2): 87-93. doi 10.1016/j.healthpol.2017.12.002].

19. Liu JX, Goryakin Y, Maeda A. et al. Global Health Workforce Labor Market Projections for 2030. Hum Resour Health. 2017; 15: 18. doi:10.1186/s12960-017-0187-2.

20. Marini MM, Fan P-L, Finley E, Beutel AM. Gender and job values. Sociol. Educ. 1996; 69: 49-65.

21. Ono T, Lafortune G, Schoenstein M. Health Workforce Planning in OECD Countries: A Review of 26 Projection Models from 18 Countries. OECD Health Working Papers. No. 62. OECD, Paris; 2013

22. Shweikeh F, Schwed AC, Hsu C, Nfonsam VN. Status of Resident Attrition From Surgical Residency in the Past, Present, and Future Outlook. J of Surg Educ. 2018;75(2): 254-262. doi.org/10.1016/j.jsurg.2017.07.015.

23. Solnick SL. Changes in women's majors from entrance to graduation at women's and coeducational colleges. Ind. Labor Relat. Rev. 1995; 48:505-14

24. Sullivan MC et al. Surgical Residency and Attrition: Defining the Individual and Programmatic Factors Predictive of Trainee Losses. J of Am Coll of Surg. 2013; 216.3: 461-471.

25. Van de Werfhorst HG, Kraaykamp G. Four field-related educational resources and their impact on labor, consumption and sociopolitical orientation. Sociol. Educ. 2001; 74(4): 296-317.

26. WHO. Health workforce requirements for universal health coverage and the Sustainable Development Goals. Human Resources for Health Observer. 2016; 17.

27. Yaghoubian A, Galante J, Kaji A, et al. General Surgery Resident Remediation and Attrition: A Multi-institutional Study. Arch Surg. 2012; 147(9): 829-833. doi:https://doi-org.proxy.uba.uva.nl:2443/10.1001/archsurg.2012.1676.

\section{Table}

Table 1. List of hospital-based specialty training program: number of males $(M)$ and females $(F)$ in training in the period 2003-2013 and their respective attrition rates, \% females in training, difference in attrition rate, type of training, \% male professionals, \% of males in training and duration (in years)

Page 9/14 


\begin{tabular}{|c|c|c|c|c|c|c|c|c|c|c|c|c|}
\hline $\begin{array}{l}\text { seciality } \\
\text { aining program }\end{array}$ & $\begin{array}{r}\text { Number } \\
\text { of } \\
\text { enrolees- } \\
\text { Males }\end{array}$ & $\begin{array}{r}\text { Attrition } \\
\text { rate- } \\
\text { Males }\end{array}$ & $\begin{array}{r}\text { Number } \\
\text { of } \\
\text { enrolees- } \\
\text { Females }\end{array}$ & $\begin{array}{l}\text { Attrition } \\
\text { rate- } \\
\text { Females }\end{array}$ & $\begin{array}{r}\text { Total } \\
\text { enrolees }\end{array}$ & $\begin{array}{r}\text { Total } \\
\text { attrition } \\
\text { rate }\end{array}$ & $\begin{array}{l}\text { Percentage } \\
\text { of females } \\
\text { in training }\end{array}$ & $\begin{array}{r}\text { Difference } \\
\text { in } \\
\text { attrition } \\
\text { rates (M } \\
\text { minus F) }\end{array}$ & $\begin{array}{l}\text { Type of } \\
\text { training }\end{array}$ & $\begin{array}{r}\% M \text { in } \\
\text { profession } \\
1 / 1 / 2003\end{array}$ & $\begin{array}{r}\% M \text { in } \\
\text { training } \\
\text { per } \\
1 / 1 / 2003\end{array}$ & $\begin{array}{r}\text { Duration } \\
\text { of } \\
\text { training } \\
\text { (years) }\end{array}$ \\
\hline raesthesiology & 388 & $8.5 \%$ & 414 & $8.5 \%$ & 802 & $8.5 \%$ & $51.6 \%$ & $0.05 \%$ & Auxiliary & $76.5 \%$ & $57.31 \%$ & 5,4 \\
\hline ardiology & 398 & $8.8 \%$ & 219 & $16.4 \%$ & 617 & $11.5 \%$ & $35.5 \%$ & $-7.64 \%$ & $\begin{array}{r}\text { Non- } \\
\text { surgical }\end{array}$ & $88.6 \%$ & $71.5 \%$ & 6,4 \\
\hline $\begin{array}{l}\text { ardiothoracic } \\
\text { Irgery }\end{array}$ & 50 & $8.0 \%$ & 12 & $50.0 \%$ & 62 & $16.1 \%$ & $19.4 \%$ & $-42.00 \%$ & Surgical & $93.1 \%$ & $66.6 \%$ & 5,9 \\
\hline inical Genetics & 13 & $23.1 \%$ & 95 & $17.9 \%$ & 108 & $18.5 \%$ & $88.0 \%$ & $5.18 \%$ & Auxiliary & $36.1 \%$ & $18.8 \%$ & 5 \\
\hline inical geriatrics & 36 & $33.3 \%$ & 185 & $19.5 \%$ & 221 & $21.7 \%$ & $83.7 \%$ & $13.87 \%$ & $\begin{array}{r}\text { Non- } \\
\text { surgical } \\
\end{array}$ & $42.9 \%$ & $35.7 \%$ & 5,9 \\
\hline rrmatology & 86 & $7.0 \%$ & 207 & $7.2 \%$ & 293 & $7.2 \%$ & $70.6 \%$ & $-0.27 \%$ & $\begin{array}{r}\text { Non- } \\
\text { surgical } \\
\end{array}$ & $68.3 \%$ & $39.4 \%$ & 5,3 \\
\hline $\begin{array}{l}\text { Ir nose throat } \\
\text { edicine } \\
\end{array}$ & 126 & $7.9 \%$ & 115 & $9.6 \%$ & 241 & $8.7 \%$ & $47.7 \%$ & $-1.63 \%$ & Surgical & $90.3 \%$ & $65.9 \%$ & 5,2 \\
\hline astroenterology & 161 & $3.7 \%$ & 177 & $6.8 \%$ & 338 & $5.3 \%$ & $52.4 \%$ & $-3.05 \%$ & $\begin{array}{r}\text { Non- } \\
\text { surgical } \\
\end{array}$ & $88.5 \%$ & $53.9 \%$ & 6,5 \\
\hline 2neral surgery & 445 & $6.7 \%$ & 259 & $18.5 \%$ & 704 & $11.1 \%$ & $36.8 \%$ & $-11.79 \%$ & Surgical & $92.3 \%$ & $69.7 \%$ & 6,2 \\
\hline ternal Medicine & 438 & $10.7 \%$ & 958 & $15.9 \%$ & 1396 & $14.3 \%$ & $68.6 \%$ & $-5.14 \%$ & $\begin{array}{r}\text { Non- } \\
\text { surgical } \\
\end{array}$ & $75.8 \%$ & $44.7 \%$ & 6,8 \\
\hline $\begin{array}{l}\text { edical } \\
\text { icrobiology }\end{array}$ & 66 & $16.7 \%$ & 96 & $11.5 \%$ & 162 & $13.6 \%$ & $59.3 \%$ & $5.21 \%$ & Auxiliary & $66.2 \%$ & $56.0 \%$ & 5,4 \\
\hline əurology & 193 & $6.7 \%$ & 345 & $9.0 \%$ & 538 & $8.2 \%$ & $64.1 \%$ & $-2.25 \%$ & $\begin{array}{r}\text { Non- } \\
\text { surgical }\end{array}$ & $81.3 \%$ & $46.0 \%$ & 6,7 \\
\hline zurosurgery & 47 & $4.3 \%$ & 20 & $15.0 \%$ & 67 & $7.5 \%$ & $29.9 \%$ & $-10.74 \%$ & Surgical & $94.0 \%$ & $88.6 \%$ & 6,2 \\
\hline $\begin{array}{l}\text { sstetrics and } \\
\text { 'naecology }\end{array}$ & 104 & $1.9 \%$ & 407 & $7.6 \%$ & 511 & $6.5 \%$ & $79.6 \%$ & $-5.69 \%$ & Surgical & $70.5 \%$ & $26.8 \%$ & 6,7 \\
\hline shthalmology & 118 & $10.2 \%$ & 162 & $7.4 \%$ & 280 & $8.6 \%$ & $57.9 \%$ & $2.76 \%$ & Surgical & $68.5 \%$ & $40.2 \%$ & 5,2 \\
\hline $\begin{array}{l}\text { thopaedic } \\
\text { Irgery }\end{array}$ & 363 & $8.5 \%$ & 102 & $20.6 \%$ & 465 & $11.2 \%$ & $21.9 \%$ & $-12.05 \%$ & Surgical & $97.1 \%$ & $82.7 \%$ & 6,2 \\
\hline yediatrics & 123 & $4.9 \%$ & 408 & $6.1 \%$ & 531 & $5.8 \%$ & $76.8 \%$ & $-1.25 \%$ & $\begin{array}{r}\text { Non- } \\
\text { surgical } \\
\end{array}$ & $54.5 \%$ & $27.8 \%$ & 5 \\
\hline athology & 100 & $16.0 \%$ & 144 & $15.3 \%$ & 244 & $15.6 \%$ & $59.0 \%$ & $0.72 \%$ & Auxiliary & $72.9 \%$ & $40.8 \%$ & 5,6 \\
\hline astic surgery & 81 & $4.9 \%$ & 75 & $1.3 \%$ & 156 & $3.2 \%$ & $48.1 \%$ & $3.60 \%$ & Surgical & $87.9 \%$ & $59.7 \%$ & 6,3 \\
\hline sychiatry & 573 & $11.7 \%$ & 1007 & $11.1 \%$ & 1580 & $11.3 \%$ & $63.7 \%$ & $0.57 \%$ & $\begin{array}{r}\text { Non- } \\
\text { surgical } \\
\end{array}$ & $67.5 \%$ & $40.3 \%$ & 4,9 \\
\hline $\begin{array}{l}\text { גmonary } \\
\text { seases }\end{array}$ & 173 & $11.6 \%$ & 274 & $19.0 \%$ & 447 & $16.1 \%$ & $61.3 \%$ & $-7.42 \%$ & $\begin{array}{r}\text { Non- } \\
\text { surgical } \\
\end{array}$ & $83.3 \%$ & $51.1 \%$ & 6,5 \\
\hline $\begin{array}{l}\text { Idiology and } \\
\text { Iclear medicine }\end{array}$ & 486 & $11.5 \%$ & 368 & $12.0 \%$ & 854 & $11.7 \%$ & $43.1 \%$ & $-0.4 \%$ & Auxiliary & $84.3 \%$ & $59.7 \%$ & 5,5 \\
\hline diotherapy & 50 & $16.0 \%$ & 131 & $9.9 \%$ & 181 & $11.6 \%$ & $72.4 \%$ & $6.08 \%$ & Auxiliary & $69.3 \%$ & $37.0 \%$ & 5,5 \\
\hline leumatology & 63 & $15.9 \%$ & 167 & $16.8 \%$ & 230 & $16.5 \%$ & $72.6 \%$ & $-0.89 \%$ & $\begin{array}{r}\text { Non- } \\
\text { surgical }\end{array}$ & $66.3 \%$ & $34.0 \%$ & 6,8 \\
\hline $\begin{array}{l}\text { evalidation } \\
\text { edicine }\end{array}$ & 72 & $25.0 \%$ & 250 & $16.0 \%$ & 322 & $18.0 \%$ & $77.6 \%$ & $9.00 \%$ & $\begin{array}{r}\text { Non- } \\
\text { surgical } \\
\end{array}$ & $60.5 \%$ & $19.2 \%$ & 4,3 \\
\hline ology & 115 & $7.0 \%$ & 114 & $11.4 \%$ & 229 & $9.2 \%$ & $49.8 \%$ & $-4.45 \%$ & Surgical & $96.3 \%$ & $63.4 \%$ & 6,1 \\
\hline ital & 4,868 & $9.7 \%$ & 6711 & $12.3 \%$ & 11579 & $11.2 \%$ & $58.0 \%$ & $-2.67 \%$ & & $75.5 \%$ & $50.7 \%$ & \\
\hline
\end{tabular}

\section{Figures}




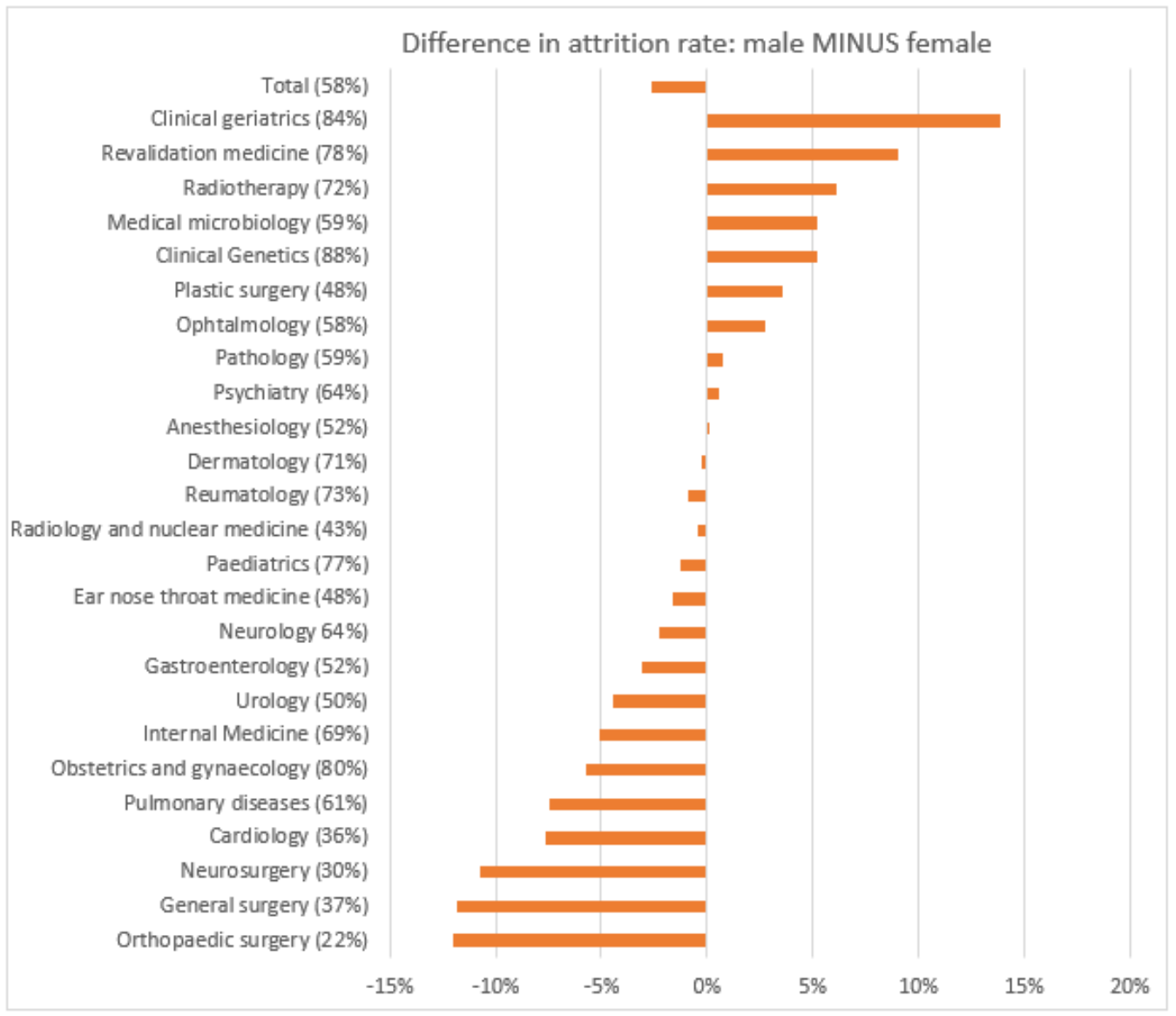

\section{Figure 1}

Difference between male and female attrition rate (male rate minus female rate), 2003-2013, by speciality and sorted by \% of female trainees

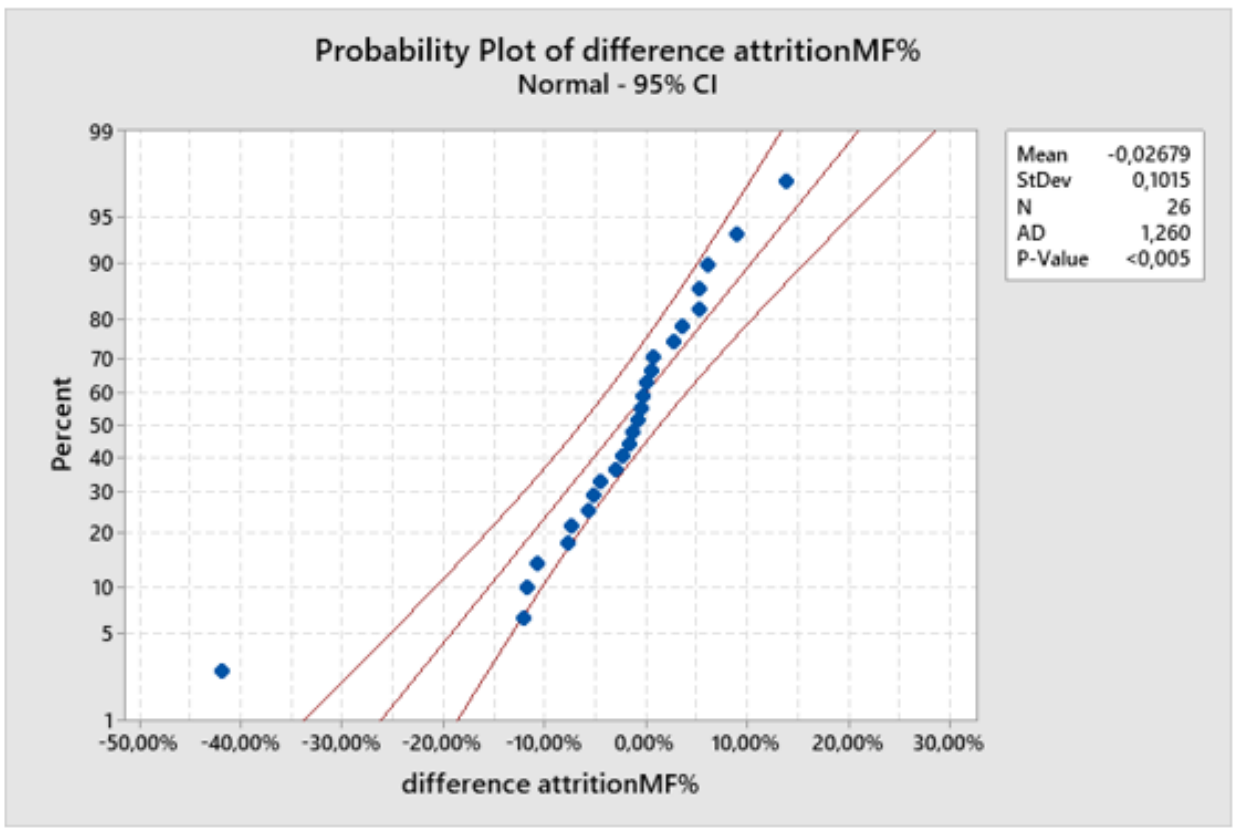

Figure 2

Probability plot for normal distribution of the male-female difference in attrition (2003-2013), including cardiothoracic surgery. 


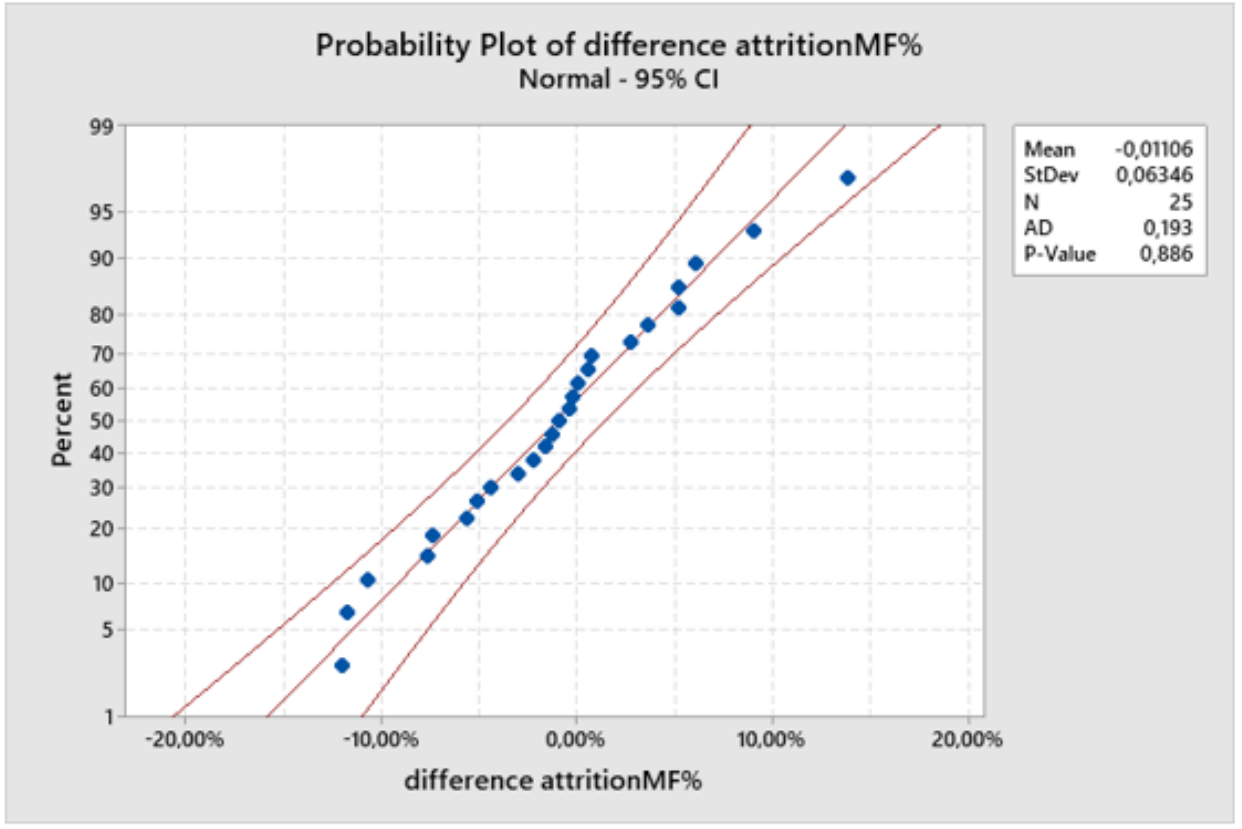

\section{Figure 3}

Probability plot for normal distribution of the male-female difference in attrition (2003-2013), excluding cardiothoracic surgery.

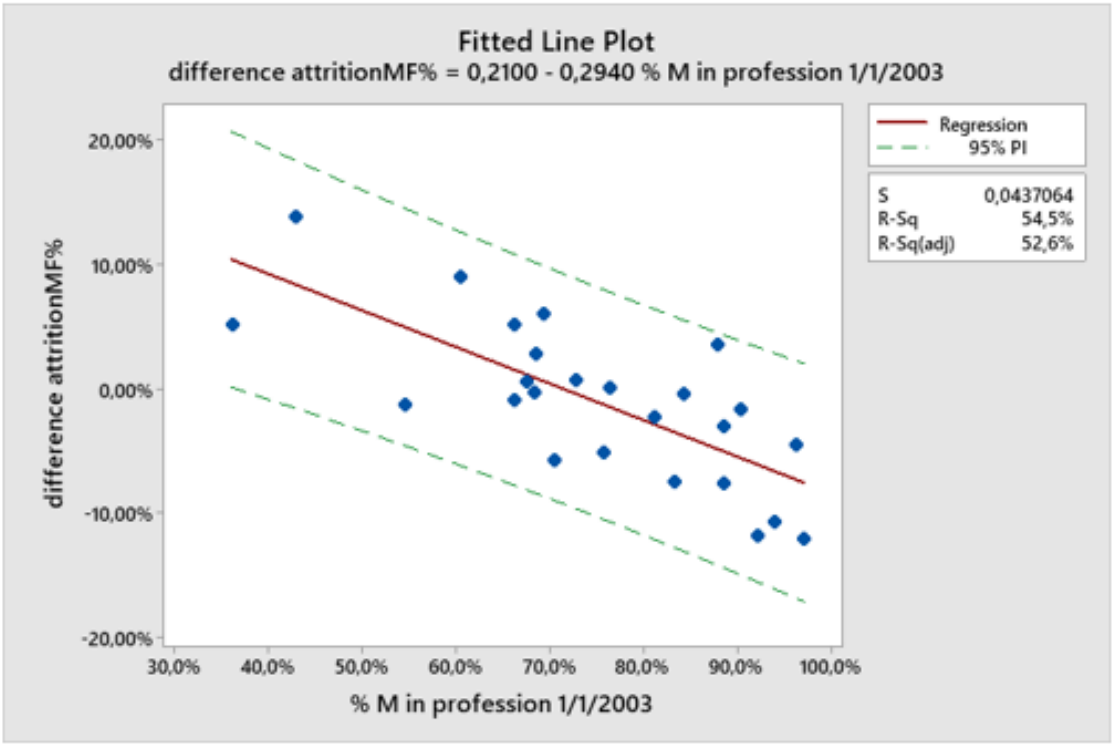

\section{Figure 4}

Linear regression analysis for the difference in attrition between males and females in training, and the proportion of males working within the specialty $(n=25)$ 


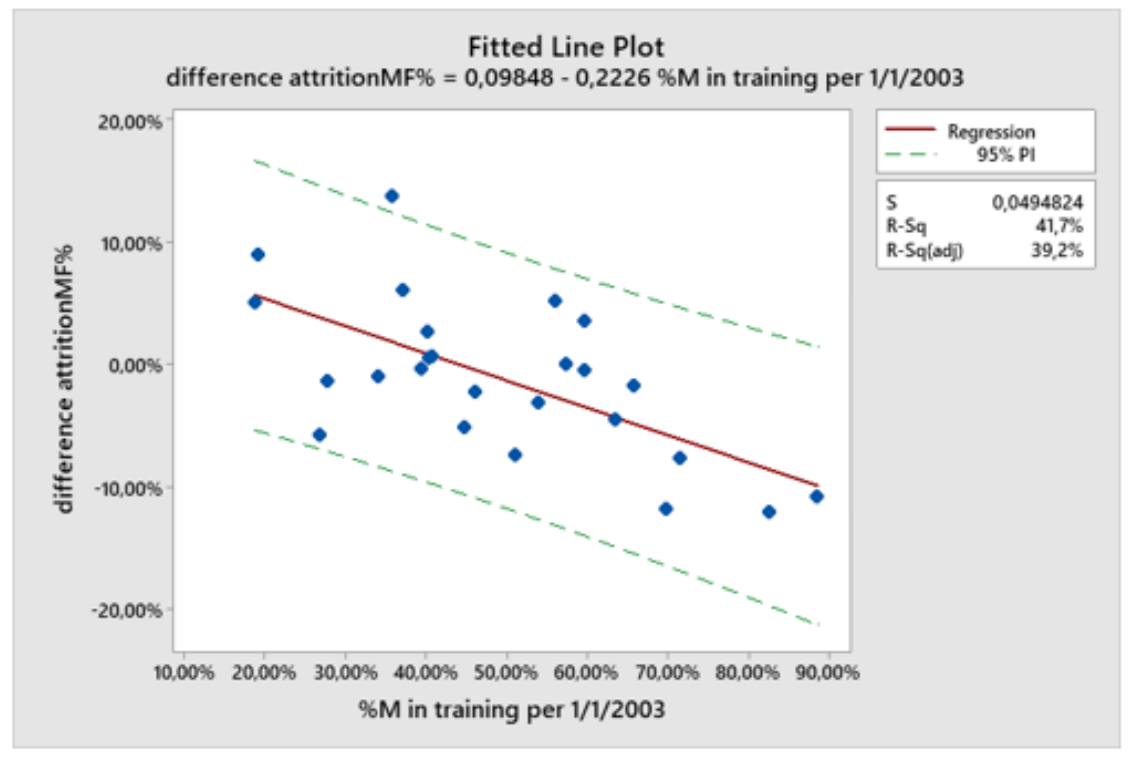

\section{Figure 5}

Linear regression analysis for the difference in attrition between males and females in training and the proportion of males in training for the specialty $(n=25)$.

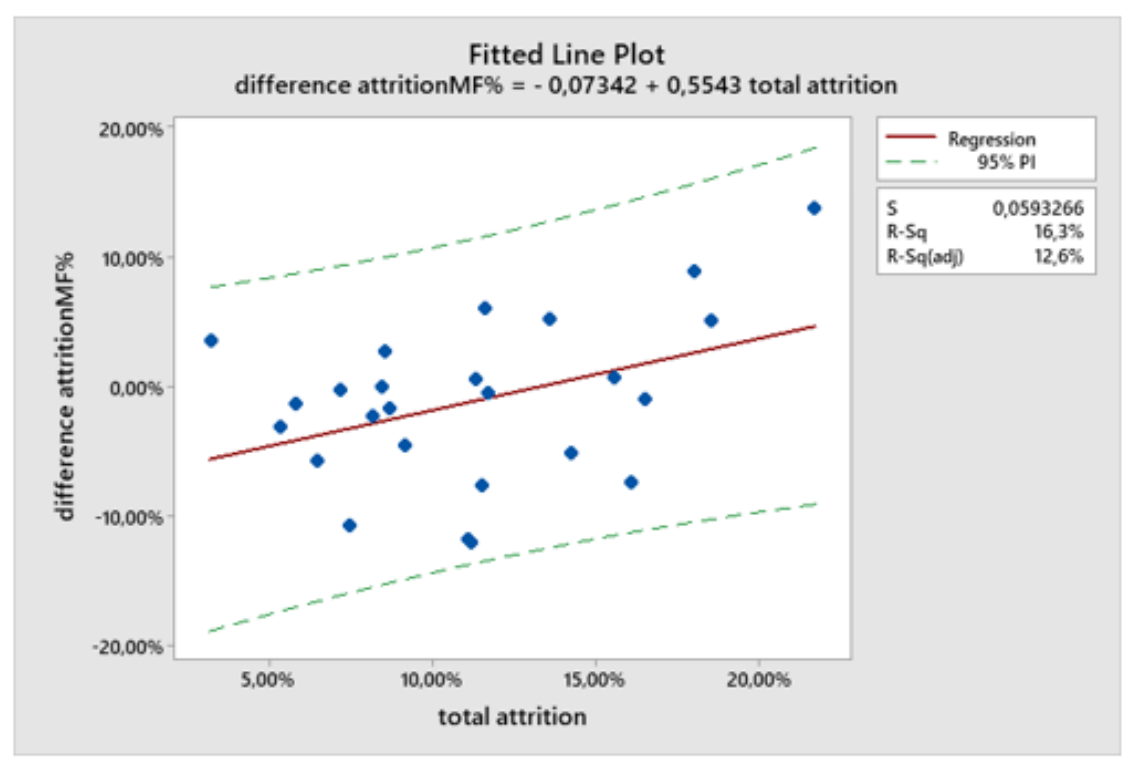

\section{Figure 6}

Linear regression analysis for the difference in attrition between males and females in training and the total attrition rate of the specialty training $(n=25)$ 


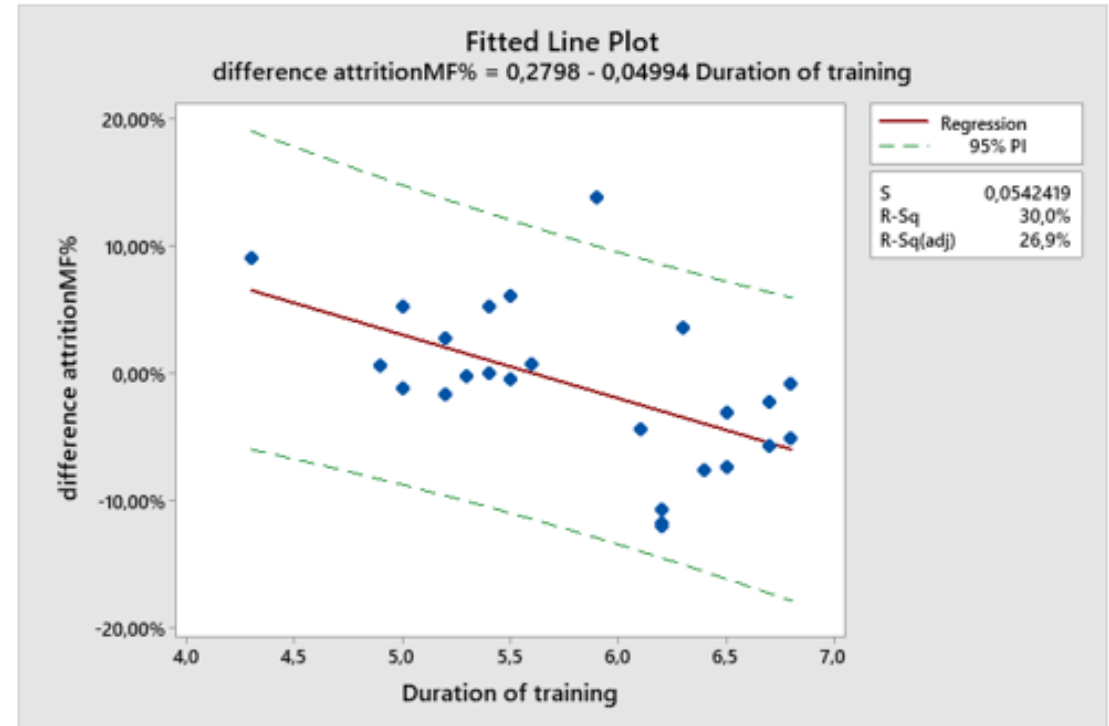

Figure 7

Linear regression analysis for difference in attrition between males and females in training and the duration of specialty training. 